\title{
The Value of Nutritional Status in the Prognostic Analysis of Patients with AIDS-Related Lymphoma
}

This article was published in the following Dove Press journal:

Infection and Drug Resistance

\author{
Yanbo Sun ${ }^{1} *$ \\ Jing Luo ${ }^{2, *}$ \\ Chuan Qian ${ }^{3, *}$ \\ Lan Luo ${ }^{3}$ \\ Manqi Xu' \\ Haiyan Min $^{3}$ \\ Yunyun Cen'
}

'Department of Gastrointestinal Surgery,

The Second Affiliated Hospital of Kunming Medical University, Kunming, 650101, People's Republic of China; ${ }^{2}$ Department of Gastrointestinal Surgery, The First People's Hospital of Qujing, Qujing, 655000, People's Republic of China; ${ }^{3}$ The Second Department of Infection, Yunnan Provincial Infectious Disease Hospital, Kunming, 65030I, People's Republic of China

*These authors contributed equally to this work
Correspondence: Yunyun Cen

Department of Gastrointestinal Surgery,

The Second Affiliated Hospital of

Kunming Medical University, No. 374 of

Yunnan-Burma Road, Kunming City,

Yunnan Province, 650I0I, People's

Republic of China

Tel +86-87I-63402778

Fax +86-87I-6536I0I7

Email drcenyunyun@163.com

Haiyan Min

The Second Department of Infection, Yunnan Provincial Infectious Disease

Hospital, Shi'an Highway in Kunming, Kunming City, Kunming, Yunnan Province, 65030I, People's Republic of China

$\mathrm{Tel} / \mathrm{Fax}+86-87 \mathrm{I}-68728053$

Email min_haiy23an@I26.com
Objective: Many studies have suggested that indexes of nutritional status, such as body mass index (BMI), serum albumin (ALB), serum pre-albumin (PA), and hemoglobin, may be used as risk factors for the prognosis of HIV or lymphoma. Therefore, this study aimed to retrospectively analyze and explore the value of nutritional status in the prognostic assessment of patients with AIDS-related lymphoma (ARL).

Methods: In this retrospective study, the clinical data of 69 patients with ARL were collected. All patients had a definite diagnosis of non-Hodgkin lymphoma by pathological examination and met the requirements of the Hematopoietic and Lymphocytic Tissue Tumor Classification (2016) established by the World Health Organization. Patients who did not receive standard chemotherapy, those with incomplete medical records, and those with an unclear pathological diagnosis were excluded. The patients were divided into two groups (survival and death) according to the prognostic outcome, and their clinical characteristics and prognoses were discussed by relevant statistical methods.

Results: During the three-year follow-up period, 20 (28.99\%) patients died, and 49 (71.01\%) survived. The one-year cumulative survival rate was $78.26 \%$. A univariate analysis found that the prognosis was associated with the International Prognostic Index (IPI) score, BMI, ALB, PA, and CD4 T lymphocyte count. The Cox risk proportional regression analysis showed that the IPI score, BMI, and PA were the independent risk factors for survival; their combination had a greater ability to forecast the clinical outcome (area under the curve $=$ $0.874, \mathrm{P}<0.001)$.

Conclusion: In this study, at the time of the visit, the patients with ARL tended to be in the advanced stages of disease and, therefore, at high risk of mortality. Therefore, their nutritional status might be of great value to the prognostic assessment. The combination of BMI, PA, and IPI scores could be used for risk stratification and better screening of high-risk patients.

Keywords: AIDS-related lymphoma, body mass index, pre-albumin, prognostic factor, retrospective analysis

\section{Introduction}

The introduction of highly active antiretroviral therapy (cART) has dramatically improved the survival quality, immune function, and life expectancy of patients with HIV infection and reduced the morbidity of opportunistic infections and malignant tumors. However, malignant lymphoma remains the primary cause of AIDS-related death and the most common malignant neoplasm. ${ }^{1,2}$ Since the $1980 \mathrm{~s}$, non-Hodgkin lymphoma (NHL) has been considered an AIDS-defining cancer and nominated as an AIDS-related lymphoma (ARL). ${ }^{3,4}$ In the pre-cART era, the risk of 
NHL in HIV-positive patients was 60-200 times higher than that in the general population, and $16 \%$ of patients with AIDS died from ARL. ${ }^{5-7}$

Patients with ARL have a high incidence of immunodeficiency and malnutrition due to the coexistence of HIV infection and lymphoma, both of which are chronic immunodepleting diseases. Due to its insidious onset in the early stages, ARL is usually in stage III or IV at the time of confirmed diagnosis, with B symptoms as the main manifestation. Malnutrition is common in patients with ARL; this not only accelerates the disease progression but also causes a certain risk of antiviral and chemotherapy toxicity, which is correlated with the survival rate in prognosis. ${ }^{8-10}$ Currently, many studies suggest that indexes of nutritional status, such as body mass index (BMI), serum albumin (ALB), serum pre-albumin (PA), and hemoglobin $(\mathrm{Hb})$, may be used as risk factors for the prognosis of HIV or lymphoma. ${ }^{11-15}$ Therefore, in this study, a retrospective analysis was conducted and relevant data collected and combined with the prognostic factors of lymphoma to explore the value and significance of nutritional status in the prognostic assessment of ARL.

\section{Patients Materials and Methods Study Subjects}

This study enrolled 69 patients with ARL who were admitted to the hospital from January 2017 to January 2019. The AIDS diagnosis had been confirmed by a local center or the Yunnan Provincial Center for Disease Control and Prevention and met the standards of the 2018 AIDS Diagnosis and Treatment Guidelines and the HIV/AIDS Diagnostic Criteria and Treatment Principles. ${ }^{16}$ All patients had a definite diagnosis of NHL by pathological examination and met the requirements of the Hematopoietic and Lymphocytic Tissue Tumor Classification (2016) established by the World Health Organization (WHO). ${ }^{17}$ Patients who did not receive standard chemotherapy, those with incomplete medical records, and those with an unclear pathological diagnosis were excluded. The standardized cART + CHOP/diffuse large B-cell lymphoma (DLBCL) R-CHOP therapy was conducted in all enrolled patients with a definite diagnosis confirmation and followed up through hospitalization, outpatient review, or telephone interview. The deadline for the follow-up was January 2020. Two cases were lost during the threeyear follow-up for a follow-up rate of $97.10 \%$. For those lost during follow-up, the last follow-up date was taken as the end time. The median follow-up time was 16 months, with a range of 12-34 months.

The patients' hospital infectious disease specialist hospital in Yunnan Province as the third rate of infectious disease specialist hospital, Kunming Medical University affiliated hospital of infectious diseases, is the national WeiJianWei and AIDS antiviral treatment training base in Yunnan Province for HIV/AIDS clinical diagnosis, treatment of infectious diseases and related services for diseases, professional training, technical guidance, scientific research, foreign exchange and cooperation, and other public health functions. The department of patient treatment is a key clinical specialty in Yunnan Province.

\section{Methods}

The patients' BMI, ALB, PA, Hb, absolute lymphocyte count (ALC), CD4, lactate dehydrogenase, Ann Arbor stage of lymphoma, pathological subtype, International Prognostic Index (IPI) of lymphoma, and cART treatment information (if received) were collected and sorted. The patients were divided into the group that survived and the group that died.

\section{Nutritional Indexes}

According to European Society for Parenteral and Enteral Nutrition (ESPEN), BMI is the ratio of weight to height squared $\left(\mathrm{kg} / \mathrm{m}^{2}\right)$. The nutritional status was divided into four levels, i.e., normal nutritional status and mild, moderate, and severe malnutrition, according to the BMI cutoff point: $\geq 18.5 \mathrm{~kg} / \mathrm{m}^{2}$ (normal), $17-18.4 \mathrm{~kg} / \mathrm{m}^{2}$ (light), $16-16.9 \quad \mathrm{~kg} / \mathrm{m}^{2} \quad$ (medium), $\quad<16 \quad \mathrm{~kg} / \mathrm{m}^{2} \quad$ (heavy), respectively. ${ }^{15,18,19}$ Malnutrition was defined as ALB $<35$ $\mathrm{g} / \mathrm{L}, \mathrm{PA}<170 \mathrm{mg} / \mathrm{L}$, and $\mathrm{Hb}<120 \mathrm{~g} / \mathrm{L}^{15,20,21}$

\section{Statistical Analysis}

The SPSS 22.0 software was used for the statistical analysis. The Kaplan-Meier method was used for the univariate analysis of prognosis, and the Log rank test was used for comparison between groups. The variables with $\mathrm{P}<$ 0.05 in the univariate analysis were included in the multivariate analysis. The Cox regression model was adopted for the multivariate analysis of prognosis, and the screened factors were introduced into the logistic regression equation to calculate the prediction probability of an outcome and draw the receiver operating characteristic (ROC) curve. The area under the curve (AUC) was compared, 
and a value of $\mathrm{P}<0.05$ was considered statistically significant.

\section{Results}

\section{General Characteristics and Clinical Features}

Among the 69 patients with ARL, 57 (82.61\%) were male and $12(17.39 \%)$ female, with a male/female ratio of 4.75:1. The age ranged between 21 and 73 years, with a median age of 48; among the patients, 9 were older than $60(13.04 \%)$. In total, 35 cases $(50.72 \%)$ were found to be HIV-positive with concomitant lymphoma. The average duration for 34 of the patients to develop ARL after HIV infection was 53.03 months, with the longest duration being 168 months. The main route of HIV infection was sexual transmission in 58 cases $(84.06 \%)$, followed by intravenous drug use in 7 cases $(10.1 \%)$ and blood transfusion and surgical history in 3 cases $(4.35 \%)$. There were four cases involving couples among those with sexual transmission of HIV. Regarding Ann Arbor stages I, II, III, and IV, there were 5 cases (7.2\%), 11 cases (15.9\%), 18 cases (26\%), and 35 cases (50.7\%), respectively. At the time of diagnosis, $53(76.81 \%)$ cases were at stage III or IV. Considering the IPI score, there were 10 cases with low risk, 21 (30.4\%) cases with moderate to low risk, 24 (34.8\%) cases with moderate to high risk, and 14 (20.3\%) cases with high risk. Thus, 38 (55.07\%) cases had moderate to high or high risk. In $33(47.82 \%)$ cases, the patients had started cART before the diagnosis of ARL. The pathological subtype was mainly DLBCL at 59 cases (85.51\%). There were also six cases with Burkitt lymphoma, one case with plasmablastic lymphoma, and three cases with unclassified NHL of the B-cell source.
Of the 20 patients who died, 16 were male $(80.00 \%)$, and 4 were female $(20.00 \%)$; the male/ female ratio was $4: 1$. Three were patients $(33.33 \%)$ aged older than 60 . There were 49 cases in the survival group, with 41 males (83.67\%) and eight females $(16.33 \%)$; the male/female ratio was $5.13: 1$. Six were patients $(66.67 \%)$ aged older than 60 . In the death group, the nutritional and immune indicators, including BMI, ALB, PA, Hb, ALC, and CD4, were all lower than those in the survival group (Table 1). In both groups, DLBCL was the most common pathological type. In the death group, the composition ratio of patients in Ann Arbor stages III/IV and the IPI score of those with moderate to high risk or high risk were greater than those in the survival group, while the rate of using cART was the opposite (Table 2).

\section{Univariate Analysis of the Prognostic Factors for ARL}

Among the 69 patients included in the study, the date of diagnosis of ARL was used as the start time, the deadline date of follow-up as the end time, and the clinical outcome as the end event. The patients were divided into the survival and death groups, with an estimated one-year survival rate of $78.26 \%$. The IPI score, BMI, ALB $<35 \mathrm{~g} / \mathrm{L}$, PA $<170 \mathrm{mg} / \mathrm{L}$, and CD4 T lymphocyte count of $<200$ cells/ $\mu \mathrm{L}$ were found to be correlated with the clinical outcomes of ARL by the univariate analysis using the Kaplan-Meier method. The differences between the groups were statistically significant. Gender, age $\geq 60$ years, $\mathrm{Hb} \geq 120 \mathrm{~g} / \mathrm{L}$, ALC $\geq 1 \times 10^{9} / \mathrm{L}$, elevated Lactic Dehydrogenase (LDH), the Ann Arbor stage, the pathology type, and previous uptake of regular cART were not correlated with the

Table I Nutritional and Immune Functional Indexes of 69 Patients with ARL with Different Clinical Outcomes ( $\bar{x} \pm s)$

\begin{tabular}{|c|c|c|c|c|c|c|}
\hline & $\begin{array}{c}\text { Total Median } \\
\text { (Inter-Quartile Range) }\end{array}$ & $\begin{array}{c}\text { Death Median } \\
\text { (Inter-Quartile Range) }\end{array}$ & $\begin{array}{c}\text { Survival Median } \\
\text { (Inter-Quartile Range) }\end{array}$ & Death & Survival & $\mathbf{P}$ \\
\hline $\operatorname{BMI}\left(\mathrm{Kg} / \mathrm{m}^{2}\right)$ & 19.81 (18.27-23.38) & $18.76(17.12-19.82)$ & $21.00(18.62-23.53)$ & $19.12 \pm 3.20$ & $21.73 \pm 3.89$ & 0.010 \\
\hline $\operatorname{ALB}(g / L)$ & $37.60(30.95-41.25)$ & $30.65(27.48-37.58)$ & $39.20(35.40-42.85)$ & $31.68 \pm 7.76$ & $38.86 \pm 6.07$ & 0.000 \\
\hline $\mathrm{PA}(\mathrm{mg} / \mathrm{L})$ & $179.00(\mid 18.00-246.00)$ & $109.00(73.25-171.75)$ & $205.00(144.50-260.00)$ & $126.45 \pm 63.80$ & $204.90 \pm 74.43$ & 0.000 \\
\hline $\mathrm{Hb}(\mathrm{g} / \mathrm{L})$ & II $5.00(95.50-132.00)$ & $98.50(90.50-127.00)$ & $118.00(104.00-133.00)$ & $104.95 \pm 23.75$ & $118.45 \pm 22.95$ & 0.032 \\
\hline $\operatorname{ALC}\left(\times 10^{9} / \mathrm{L}\right)$ & $0.94(0.57-1.50)$ & $0.67(0.40-1.11)$ & $0.97(0.68-1.62)$ & $0.75 \pm 0.48$ & $1.20 \pm 0.74$ & 0.014 \\
\hline CD4(Cells $/ \mu \mathrm{L}$ ) & $162.00(96.50-240.00)$ & $101.00(53.25-163.50)$ & $193.00(123.50-267.00)$ & $121.20 \pm 106.56$ & $203.49 \pm 109.62$ & 0.006 \\
\hline
\end{tabular}

Abbreviations: BMI, body mass index; ALB, albumin; PA, prealbumin; Hb, hemoglobin; ALC, absolute lymphocyte count. 
Table 2 Univariate Analysis of the Clinical Characteristics and Prognosis of 69 Patients with ARL

\begin{tabular}{|c|c|c|c|c|}
\hline Factors & Cases 69(\%) & Survival/Death $49 / 20$ (Case) & $\chi^{2}$ & $\mathbf{P}$ \\
\hline $\begin{array}{c}\text { Gender } \\
\text { Male }\end{array}$ & $57(82.61 \%)$ & $41 / 16$ & 0.119 & 0.730 \\
\hline $\begin{array}{l}\text { Age(year) } \\
\geq 60\end{array}$ & $9(13.04 \%)$ & $6 / 3$ & 0.050 & 0.824 \\
\hline $\begin{array}{l}\text { BMI }\left(\mathrm{Kg} / \mathrm{m}^{2}\right) \\
\text { Normal }(\geq 18.5) \\
\text { Light }(17-18.4) \\
\text { Medium }(16-16.9) \\
\text { Heavy }(<16)\end{array}$ & $\begin{array}{c}49(71.01 \%) \\
16(23.19 \%) \\
2(2.90 \%) \\
2(2.90 \%)\end{array}$ & $\begin{array}{c}38 / I I \\
I I / 5 \\
0 / 2 \\
0 / 2\end{array}$ & 33.398 & 0.000 \\
\hline $\begin{array}{l}\mathrm{ALB}(g / L) \\
\quad<35\end{array}$ & $23(33.33 \%)$ & $10 / 13$ & 14.219 & 0.000 \\
\hline $\begin{array}{l}\mathrm{PA}(\mathrm{mg} / \mathrm{L}) \\
\quad<170\end{array}$ & 3 I (44.93\%) & $16 / 15$ & 11.378 & 0.001 \\
\hline $\begin{array}{r}\mathrm{Hb}(\mathrm{g} / \mathrm{L}) \\
\quad<120\end{array}$ & $4 \mathrm{I}(59.42 \%)$ & $27 / 14$ & 1.596 & 0.206 \\
\hline $\begin{array}{l}\operatorname{ALC}\left(\times 10^{9} / \mathrm{L}\right) \\
<1\end{array}$ & $44(63.77 \%)$ & $28 / 16$ & 3.555 & 0.059 \\
\hline $\begin{array}{l}\mathrm{CD} 4(\mathrm{a} / \mu \mathrm{L}) \\
\quad<200\end{array}$ & $43(62.32 \%)$ & $26 / 17$ & 6.055 & 0.014 \\
\hline $\begin{array}{l}\text { LDH } \\
\quad \text { Elevated }\end{array}$ & $46(66.67)$ & $31 / 15$ & 0.776 & 0.378 \\
\hline $\begin{array}{l}\text { Ann Arbor stage } \\
\text { III/IV }\end{array}$ & $53(76.81 \%)$ & $35 / 18$ & 2.817 & 0.093 \\
\hline $\begin{array}{l}\text { Pathological type } \\
\text { DLBCL } \\
\text { BL } \\
\text { PBL } \\
\text { Unclassified NHL }\end{array}$ & $\begin{array}{c}59(85.51 \%) \\
6(8.70 \%) \\
1(1.45 \%) \\
3(4.35 \%)\end{array}$ & $\begin{array}{c}43 / 16 \\
4 / 2 \\
1 / 0 \\
1 / 2\end{array}$ & 3.310 & 0.346 \\
\hline $\begin{array}{l}\text { IPI(score) } \\
\text { Low-risk(0/I) } \\
\text { Moderate to low risk(2) } \\
\text { Moderate to high risk(3) } \\
\text { High risk(4/5) }\end{array}$ & $\begin{array}{l}10(14.50 \%) \\
21(30.43 \%) \\
24(34.78 \%) \\
14(20.29 \%)\end{array}$ & $\begin{array}{c}9 / 1 \\
17 / 4 \\
19 / 5 \\
4 / 10\end{array}$ & 24.291 & 0.000 \\
\hline $\begin{array}{l}\text { Whether cART } \\
\text { No }\end{array}$ & $36(52.17 \%)$ & $23 / 13$ & 1.299 & 0.254 \\
\hline
\end{tabular}

Abbreviations: BMI, body mass index; ALB, albumin; PA, prealbumin; Hb, hemoglobin; ALC, absolute lymphocyte count; LDH, lactate dehydrogenase; DLBCL, diffuse large B-cell lymphoma; BL, Burkitt lymphoma; PBL, plasmablastic lymphoma; cART, highly active antiretroviral therapy.

clinical outcomes of ARL. The differences between the groups were not statistically significant (Table 2). The higher the IPI score, the lower the cumulative survival rate. However, the BMI, ALB, PA, and CD4 count were positively correlated with the cumulative survival rate (Figure 1).

\section{Multivariate Analysis of the Prognostic}

\section{Factors for ARL}

The univariates with statistical significance, e.g., IPI, BMI, $\mathrm{ALB}, \mathrm{PA}$, and CD4, were included in the multivariate Cox risk regression analysis. The results showed that IPI, BMI, and PA were risk factors affecting the prognosis of patients 

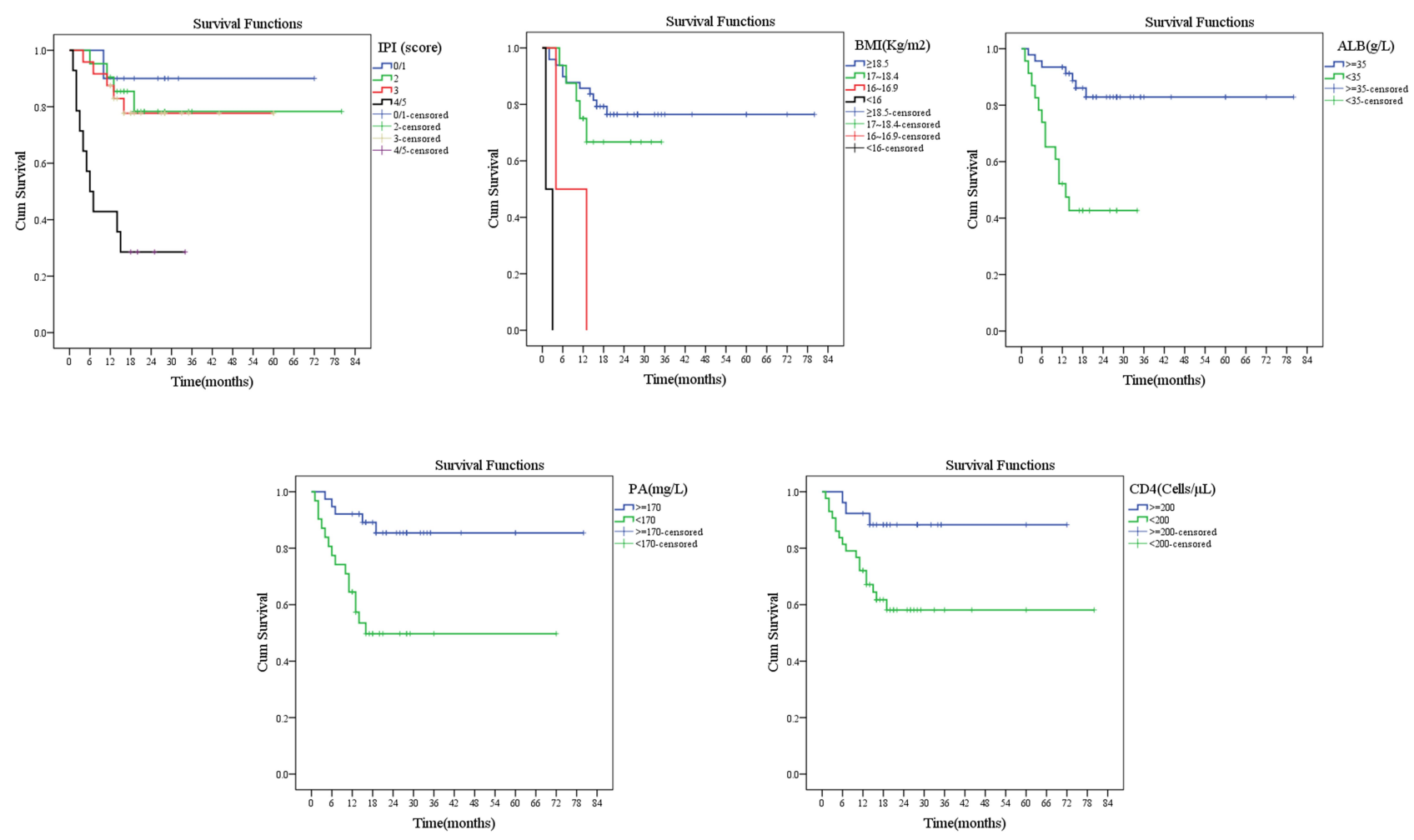

Figure I The univariate survival function diagram of IPI, BMI, ALB, PA, and CD4 by the Kaplan-Meier method.

with ARL after standard treatment. In the case of PA $<170 \mathrm{mg} / \mathrm{L}$, BMI $<16.9 \mathrm{~kg} / \mathrm{m}^{2}$, and an IPI score of high risk, the Relative Risk was $>1$ in all, and the difference was statistically significant $(\mathrm{P}<0.05)$. The difference was not statistically significant when the IPI score was moderate to low or moderate to high risk and BMI $>17 \mathrm{~kg} / \mathrm{m}^{2}$ (Table 3). The higher the IPI score, the lower the cumulative survival rate. However, the BMI and PA were positively correlated with the cumulative survival rate (Figure 2).

\section{Prognostic Value}

The IPI score, BMI, and PA were introduced into the logistic regression equation to calculate the outcome prediction probability and plot the ROC curve. Different curves and the AUC were compared. It was found that

Table 3 Parameter Estimation and Test Results of the Cox Proportional Hazards Regression Model $\left(\chi^{2}=38.107, \mathrm{P}<0.00 \mathrm{I}\right)$

\begin{tabular}{|l|c|c|c|}
\hline Factors & $\boldsymbol{\beta}$ & $\mathbf{R R ( 9 5 \% ~ C I )}$ & $\mathbf{P}$ \\
\hline Prealbumin & 1.189 & $3.285(1.074-10.044)$ & 0.037 \\
\hline IPI(Low-risk) & & Indicator & - \\
\hline IPI(Moderate to low risk) & 0.513 & $1.670(0.165-16.897)$ & 0.664 \\
\hline IPI(Moderate to high risk) & 0.782 & $2.185(0.250-19.078)$ & 0.479 \\
\hline IPI(High risk) & 2.883 & $17.873(1.972-161.960)$ & 0.010 \\
\hline BMI(normal) & & Indicator & - \\
\hline BMI(light) & 0.935 & $2.546(0.704-9.214)$ & 0.154 \\
\hline BMI(medium) & 2.560 & $12.941(1.880-89.096)$ & 0.009 \\
\hline BMI(heavy) & 2.635 & $13.940(1.730-112.306)$ & 0.013 \\
\hline
\end{tabular}

Abbreviation: BMl, body mass index. 

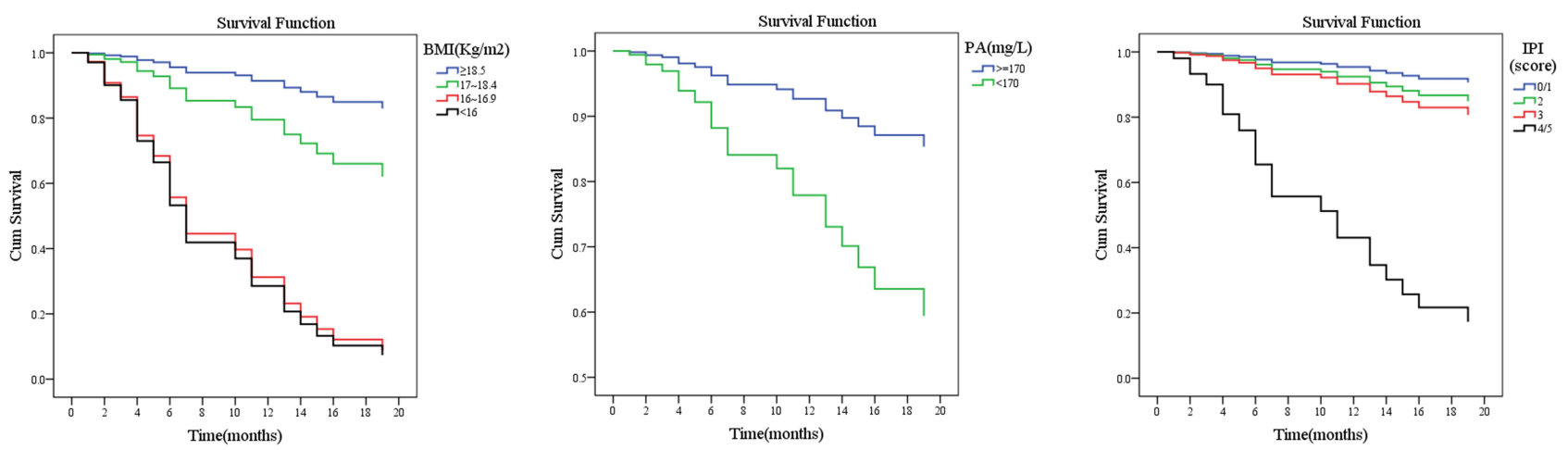

Figure 2 The multivariate survival function diagram of BMI, PA, and IPI score by the Cox risk regression analysis.

the combination of BMI, PA, and IPI was more predictive in evaluating the clinical outcome in patients with ARL, with a greater AUC than that of any single index (Table 4 and Figure 3).

\section{Discussion}

In AIDS, the CD4 T lymphocytes in the human body are continuously depleted after infection with the human immunodeficiency virus, resulting in impaired immune surveillance and barrier function. Prolonged low immune function can cause malignant changes in the immune cells, eventually leading to the development of ARL in patients with AIDS. ${ }^{22}$ These two diseases are not only causally correlated with each other but also exacerbate each other in terms of immune injury and nutritional depletion. Malnutrition is the earliest clinical symptom in patients with AIDS, with a prevalence of $98 \%$. When the disease progresses to the advanced stage, almost all patients develop varying degrees of weight loss and cachexia. ${ }^{23}$ In patients who are HIV-positive and have lymphoma, fever, and weight loss are predominant in the clinic together with the universal occurrence of malnutrition. Although the underlying mechanisms of nutritional

Table 4 The Area Under the Curve of the ROC of IPI, BMI, PA and the Composite Indicator (PA+IPI+BMI)

\begin{tabular}{|l|c|c|}
\hline Factors & AUC(95\% CI) & $\mathbf{P}$ \\
\hline IPI & $0.737(0.599-0.875)$ & 0.002 \\
\hline BMI & $0.708(0.569-0.847)$ & 0.007 \\
\hline PA & $0.790(0.675-0.905)$ & 0.000 \\
\hline $\begin{array}{l}\text { The composite indicator (PA+IPI } \\
\text { +BMI) }\end{array}$ & $0.874(0.786-0.962)$ & 0.000 \\
\hline
\end{tabular}

Abbreviations: BMI, body mass index; PA, prealbumin. alterations in cancer remain unclear, the production of catabolic factors by the cancer cells combined with the pro-inflammatory response in the host may induce energy expenditure, resulting in weight loss and, ultimately, undernutrition. ${ }^{24}$ Studies have shown a six-fold increase in mortality among patients with HIV who lose more than $10 \%$ of their body weight, even in those who undertake cART. $^{11}$

Since its formal proposal by Shipp et al in 1993, the IPI has been widely applied in the risk stratification of lymphoma. Patients with lymphoma are divided into four risk stratifications (low risk, moderate to low risk, moderate to high risk, and high risk) according to five indicators: age, LDH, Eastern Cooperative Oncology Group (ECOG) score, Ann Arbor stage, and extranodal involvement. The corresponding overall survival rate is obtained by followup. $^{25,26}$ However, while the prognosis of DLBCL

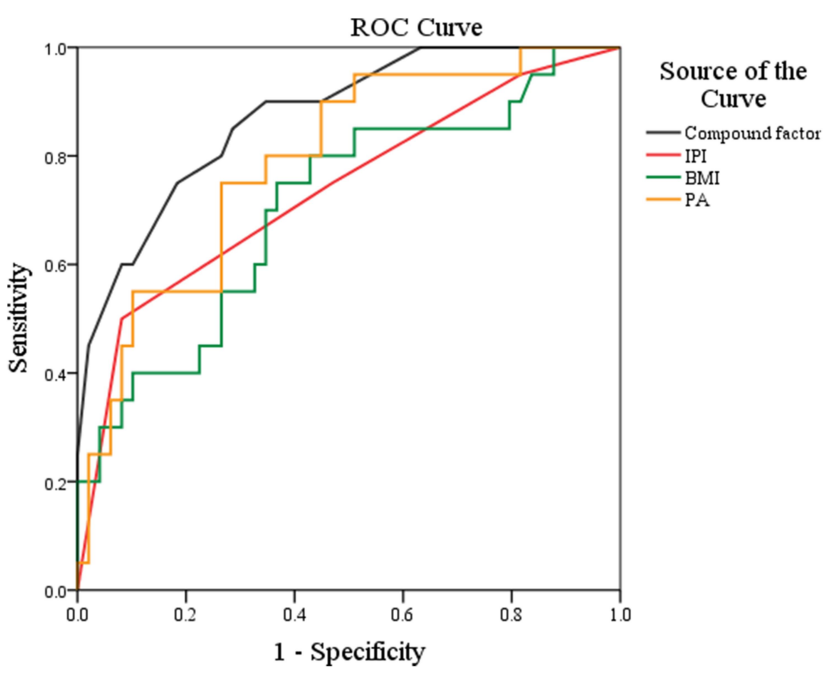

Figure 3 The ROC curve of IPI, BMI, PA, and the composite indicator (PA+IPI $+\mathrm{BMI})$. 
improves with the wide application of rituximab combined with chemotherapy, the IPI score's ability in screening the risk stratification is limited and ignores the nutritional consumption and high metabolism of cancer cells based on immunodeficiency diseases. ${ }^{27,28}$ Age and LDH level affect the evaluation of stratification indicators in IPI scoring. Most patients with ARL are younger than 60 and have a generally high LDH level, which might affect their IPI scores. In the present study, there were only 9 patients (13.04\%) older than 60; however, 46 patients (66.67\%) had elevated levels of LDH, and 31 (44.93\%) had IPI scores of low risk or moderate to low risk. Five $(12.20 \%)$ patients died one year later. Therefore, it is difficult for the IPI scoring model alone to truly distinguish the high-risk population. New or composite indicators are needed to comprehensively assess the prognosis and screen the high-risk population to guide individualized clinical diagnosis and treatment.

The WHO advocates that a BMI of less than $18.5 \mathrm{~kg} /$ $\mathrm{m}^{2}$ is the stratification standard for malnutrition, and more clinicians have started recognizing this in the assessment, risk investigation, diagnosis, and treatment guidance of clinical nutrition. Park et $\mathrm{al}^{15}$ conducted a prospective cohort study on 262 patients diagnosed with DLBCL in a medical center in Seoul, South Korea, between September 2008 and December 2011. The results suggested that BMI, ALB, PA, and other nutritional indicators could be adopted as prognostic risk factors; however, a multivariate analysis found that BMI was the only indicator that could independently predict the overall survival. Patients with hypoalbuminemia $(<3.5 \mathrm{~g} / \mathrm{L})$ are considered to have malnutrition. However, albumin has a long halflife (15-21 days) and is affected by inflammation. Bias may be caused by clinical measures of human albumin infusion to improve edema or promote wound healing. Thus, there are several controversies regarding the value of albumin in reflecting the visceral protein. ${ }^{20,29}$ While serum PA is not affected by systematic inflammation due to its short half-life (2-3 days), it is more sensitive to insufficient energy and protein intake than albumin and can better reflect the recent dietary intake. Therefore, serum PA may be used as an alternative nutritional marker and screening tool for malnutrition. ${ }^{21,30}$ Although transferrin also has a short half-life (7-10 days), its level is greatly affected by the iron level and is usually not adopted as a nutritional parameter. In the present study, there were 20 cases $(28.99 \%)$ with BMI $<18.4 \mathrm{~kg} / \mathrm{m}^{2}, 23$ cases $(33.33 \%)$ with ALB $<35$ g/L, 31 cases (44.93\%) with PA $<170$ mg/ $\mathrm{L}$, and 41 cases $(59.42 \%)$ with $\mathrm{Hb}<120 \mathrm{~g} / \mathrm{L}$.

The clinical outcome of ARL has been improved in recent years. Due to the synergistic effects of chemotherapy and antiviral therapy, the two-year survival rate can reach $60 \%{ }^{31}$ Moreover, the five-year survival rate of patients who achieve complete remission through first-line chemotherapy may be as high as $87.8 \%{ }^{32}$ Whether to undertake chemotherapy has been recognized as an independent prognostic factor for lymphoma, even in patients positive for HIV infection. However, there have been few studies on the survival analysis after chemotherapy, and there are many confounding prognostic factors that are biased and difficult to evaluate. In the present study, a retrospective analysis of the nutritional status and clinical characteristics of the 69 patients with ARL found that most patients were in the advanced stage of the disease at the time of diagnosis; stages III and IV and an IPI score $\geq 3$ were more common in these patients. Nearly one-third of the patients had a BMI lower than $18.5 \mathrm{~kg} / \mathrm{m}^{2}$, and more than half had varying degrees of malnutrition. Two patients with severe malnutrition had a poor prognosis and survived less than three months. Using the univariate $\mathrm{K}-\mathrm{M}$ method and multivariate Cox risk regression analysis, it was found that the IPI score, BMI, and PA were all risk factors for the survival and prognosis of patients with ARL and shared the same value in the evaluation of the disease development. The combination of these three indicators might be more reliable than any single factor in evaluating patients' clinical outcomes. It was also found in the present study that the CD4 count was statistically significant in the univariate analysis but became a confounding factor when introduced into the multivariate analysis and, thus, could not be used as a prognostic factor. This was consistent with Kaplan's results. ${ }^{33}$ The short follow-up duration of the present study resulted in more censored values. The research data were all from the patients during treatment, and there was a lack of data from the treatment interval and period after treatment. Therefore, a multi-center, large-sample prospective study is needed to verify the results of the present research. Once confirmed, these findings will have clinical value and play a role in the screening of high-risk patients, conduction of nutritional therapy, and development of treatment to improve survival and life expectancy.

In summary, the present research retrospectively analyzed and explored the prognostic value of nutritional status in ARL and found that patients with ARL are primarily in the advanced stage of disease at the time of diagnosis, with 
different degrees of malnutrition generally. The combination of nutritional status and IPI score could better screen and differentiate patients at high risk earlier and aid in implementing individualized treatment and nutritional intervention. The indicators of nutritional status used herein were easy to obtain and simple to operate. After further confirmation, these indicators might be expected to become prognostic indicators for clinical evaluation of and self-testing in patients.

\section{Ethics Approval and Consent to Participate}

This study was conducted with approval from the Ethics Committee of The second Affiliated Hospital of Kunming Medical University, This study was conducted in accordance with the declaration of Helsinki. Written informed consent was obtained from all participants.

\section{Acknowledgments}

We would like to acknowledge the hard and dedicated work of all the staff that implemented the intervention and evaluation components of the study.

\section{Funding}

This study was supported by Fund Project of Yunnan Surgical Clinical Nutrition Research Center (2018NS0317,2018NS0318); Basic Research Plan of Yunnan Province [Joint Project of Kunming Medical College, 2019FE001(-223),2019FE001(-167)]; Medical Reserve Personnel Training Plan of Yunnan Provincial Health Commission (H-2018067); and Funds for Talent Project of the Second Affiliated Hospital of Kunming Medical University (Special Project for Famous Doctors).

\section{Disclosure}

The authors declare that they have no competing interests.

\section{References}

1. Qiao YC, Xu Y, Jiang DX, et al. Epidemiological analyses of regional and age differences of HIV/AIDS prevalence in China, 2004-2016. Int $J$ Infect Dis. 2019;81:215-220. doi:10.1016/j.ijid.2019.02.016

2. Bruyand $M$, Thiébaut $R$, Lawson-Ayayi S, et al.; Groupe d'Epidémiologie Clinique du SIDA en Aquitaine (GECSA). Role of uncontrolled HIV RNA level and immunodeficiency in the occurrence of malignancy in HIV-infected patients during the combination antiretroviral therapy era: Agence Nationale de Recherche sur le Sida (ANRS) CO3 aquitaine cohort. Clin Infect Dis. 2009;49 (7):1109-1116. doi:10.1086/605594

3. Kang R, Li J, Chen H, et al. Using longitudinal genetic-network study to understand HIV treatment-as-prevention: a population-based observational study. AIDS. 2021. doi:10.1097/QAD.0000000000002812
4. Pather S, Mashele T, Willem P, et al. MYC status in HIV-associated Plasmablastic lymphoma: dual-colour CISH, FISH and immunohistochemistry. Histopathology. 2021. doi:10.1111/his.14336

5. Franceschi S, Lise M, Clifford GM, et al; Swiss HIV Cohort Study. Changing patterns of cancer incidence in the early- and late-HAART periods: the Swiss HIV Cohort Study. Br J Cancer. 2010;103 (3):416-422. doi:10.1038/sj.bjc.6605756

6. Siddiqui RS, Agladze M, Bashir T. Hemophagocytic lymphohistiocytosis as the presenting manifestation of relapsed classic hodgkin's lymphoma in the presence of concurrent human immunodeficiency virus, genital herpes, epstein-barr virus and mycobacterium avium complex infection. Cureus. 2020;12(11):e11563.

7. Bohlius J, Schmidlin K, Costagliola D, et al.; Collaboration of Observational HIV Epidemiological Research Europe (COHERE) study group. Prognosis of HIV-associated non-hodgkin lymphoma in patients starting combination antiretroviral therapy. AIDS. 2009;23(15):2029-2037. doi:10.1097/QAD.0b013e32832e531c

8. McMillan DC. Systemic inflammation, nutritional status and survival in patients with cancer. Curr Opin Clin Nutr Metab Care. 2009;12 (3):223-226. doi:10.1097/MCO.0b013e32832a7902

9. Li H, Q Y M, Tang SR, Shi LC. Effects of enteral nutrition support on antiviral therapy for AIDS patients. Nurs Res. 2013;27 (18): 1873-1874.

10. Mori N, Wildes F, Takagi T, Glunde K, Bhujwalla ZM. The tumor microenvironment modulates choline and lipid metabolism. Front Oncol. 2016;6:262. doi:10.3389/fonc.2016.00262

11. Hashimoto $\mathrm{N}$, Ueda $\mathrm{T}$, Hiraiwa $\mathrm{S}$, Tajiri $\mathrm{T}$, Nakamura $\mathrm{N}$, Yokoyama K. Clonally related plasmablastic lymphoma simultaneously occurring with diffuse large B-cell lymphoma. Case Rep Hematol. 2020;2020:8876567. doi:10.1155/2020/8876567

12. Zhou Q, Wei Y, Huang F, et al. Low prognostic nutritional index predicts poor outcome in diffuse large B-cell lymphoma treated with R-CHOP. Int J Hematol. 2016;104(4):485-490. doi:10.1007/s12185016-2052-9

13. Hao X, Wei Y, Wei X, et al. Glasgow prognostic score is superior to other inflammation-based scores in predicting survival of diffuse large B-cell lymphoma. Oncotarget. 2017;8(44):76740-76748. doi:10.18632/oncotarget.20832

14. Miura K, Konishi J, Miyake T, et al. A host-dependent prognostic model for elderly patients with diffuse large B-cell lymphoma. Oncologist. 2017;22(5):554-560. doi:10.1634/theoncologist.2016-0260

15. Park S, Han B, Cho JW, et al. Effect of nutritional status on survival outcome of diffuse large B-cell lymphoma patients treated with rituximab-CHOP. Nutr Cancer. 2014;66(2):225-233. doi:10.1080/ 01635581.2014.867065

16. Chinese Center for Disease Control and Prevention, AIDS and Hepatitis C Group, Chinese Association of Infectious Diseases. Chinese Medical Association Chinese guidelines for diagnosis and treatment of HIV/AIDS. Electron J Emerg Infect Dis. 2018;2018(6).

17. Duan R. WHO classification of hematopoietic and lymphoid tumors. Chin J Diagn Pathol. 2016;2017(12):956-958.

18. Cederholm T, Bosaeus I, Barazzoni R, et al. Diagnostic criteria for malnutrition - an ESPEN consensus statement. Clin Nutr. 2015;34 (3):335-340. doi:10.1016/j.clnu.2015.03.001

19. Rondel ALMA, Langius JAE, de van der Schueren MAE, Kruizenga HM. The new ESPEN diagnostic criteria for malnutrition predict overall survival in hospitalised patients. Clin Nutr. 2018;37 (1):163-168. doi:10.1016/j.clnu.2016.11.018

20. Birlutiu V, Birlutiu RM, Zaharie IS, Sandu M. Burkitt lymphoma associated with human immunodeficiency virus infection and pulmonary tuberculosis: a case report. Medicine. 2020;99(52):e23853. doi:10.1097/MD.0000000000023853

21. Devoto G, Gallo F, Marchello C, et al. Prealbumin serum concentrations as a useful tool in the assessment of malnutrition in hospitalized patients. Clin Chem. 2006;52(12):2281-2285. doi:10.1373/ clinchem.2006.080366 
22. Ribera JM, Navarro JT. Human immunodeficiency virus-related nonhodgkin's lymphoma. Haematologica. 2008;93(8):1129-1132. doi:10.3324/haematol.13519

23. Glushko T, He L, McNamee W, Babu AS, Simpson SA. HIV lymphadenopathy: differential diagnosis and important imaging features. AJR Am J Roentgenol. 2020;1-8. doi:10.2214/AJR.19.22334

24. Gordon JN, Green SR, Goggin PM. Cancer cachexia. QJM. 2005;98 (11):779-788. doi:10.1093/qjmed/hci127

25. Ikeda H, Kobune M, Nagashima K, et al. Diffuse large B cell lymphoma with HIV infection presented with disseminated thromboembolism during antiretroviral therapy. Rinsho Ketsueki. 2020;61 (11):1595-1599. doi:10.11406/rinketsu.61.1595

26. Shipp MA. Prognostic factors in aggressive non-hodgkin's lymphoma: who has "high-risk" disease? Blood. 1994;83(5):1165-1173. doi:10.1182/blood.V83.5.1165.1165

27. Pfreundschuh M, Kuhnt E, Trümper L, et al.; MabThera International Trial (MInT) Group. CHOP-like chemotherapy with or without rituximab in young patients with good-prognosis diffuse large-B-cell lymphoma: 6-year results of an open-label randomised study of the MabThera International Trial (MInT) Group. Lancet Oncol. 2011;12 (11):1013-1022. doi:10.1016/S1470-2045(11)70235-2

28. Ziepert M, Hasenclever D, Kuhnt E, et al. Standard international prognostic index remains a valid predictor of outcome for patients with aggressive CD20+ B-cell lymphoma in the rituximab era. J Clin Oncol. 2010;28(14):2373-2380. doi:10.1200/JCO.2009.26.2493
29. Shang H, Wang L. Experimental Diagnostics. 3rd ed. Beijing: People's Medical Publishing House; 2015:172-177.

30. Ingenbleek Y, Young VR. Significance of transthyretin in protein metabolism. Clin Chem Lab Med. 2002;40(12):1281-1291. doi:10.1515/CCLM.2002.222

31. Ribera JM, Oriol A, Morgades M, et al; PETHEMA, GELTAMO, GELCAB and GESIDA Groups. Safety and efficacy of cyclophosphamide, adriamycin, vincristine, prednisone and rituximab in patients with human immunodeficiency virus-associated diffuse large B-cell lymphoma: results of a Phase II trial. Br J Haematol. 2008;140(4):411-419. doi:10.1111/j.1365-2141.2007.06943.x

32. Schommers $P$, Gillor D, Hentrich $M$, et al. Incidence and risk factors for relapses in HIV-associated non-hodgkin lymphoma as observed in the German HIV-related lymphoma cohort study. Haematologica. 2018;103(5):857-864. doi:10.3324/haematol.2017.180893

33. Kaplan LD. Management of HIV-associated hodgkin lymphoma: how far we have come. $J$ Clin Oncol. 2012;30(33):4056-4058. doi: $10.1200 /$ JCO.2012.44.8373
Infection and Drug Resistance

\section{Publish your work in this journal}

Infection and Drug Resistance is an international, peer-reviewed openaccess journal that focuses on the optimal treatment of infection (bacterial, fungal and viral) and the development and institution of preventive strategies to minimize the development and spread of resistance. The journal is specifically concerned with the epidemiology of

\section{Dovepress}

antibiotic resistance and the mechanisms of resistance development and diffusion in both hospitals and the community. The manuscript management system is completely online and includes a very quick and fair peerreview system, which is all easy to use. Visit http://www.dovepress.com/ testimonials.php to read real quotes from published authors. 